КУЗЬМИНА Т. И.

К ВОПРОСУ О ПЕРСПЕКТИВАХ ИССЛЕДОВАНИЯ САМОСОЗНАНИЯ В СПЕЦИАЛЬНОЙ ПСИХОЛОГИИ

РоссийскИй псИХологИЧЕСКИЙ ЖУРнАл, 2020, Т. 17, № 2, 5-16. doi: 10.21702/rpj.2020.2.1

КОРРЕКЦИОННАЯ ПСИХОЛОГИЯ

УдK 159.99 doi: $10.21702 /$ rpj.2020.2.1

Систематический обзор

\title{
К вопросу о перспективах исследования самосознания в специальной психологии
}

\author{
Татьяна И. Кузьмина ${ }^{1,2}$ \\ 1 Федеральное государственное бюджетное образовательное учреждение высшего образования \\ «Московский государственный психолого-педагогический университет», г. Москва, Российская \\ Федерация \\ 2 Федеральное государственное бюджетное научное учреждение «Институт коррекционной \\ педагогики Российской академии образования», г. Москва, Российская Федерация \\ E-mail: ta-1@list.ru \\ ORCID ID: https://orcid.org/0000-0003-2367-3390
}

\begin{abstract}
Аннотация
Введение. Вопросы изучения самосознания ^иц с ограниченными возможностями зАоровья сопряжены с Аиагностическими, интерпретационными, организационными трудностями. Существует научная проблема разработки единых методологических основ исслеАования Аичности при аномальном развитии.
\end{abstract}

Теоретическое обоснование. Метолология изучения внутреннего мира человека и его прелставлений о себе в контексте исслеАования психического состояния, наличия ментальных или иных нарушений опирается на три исследовательские позиции: объяснительную, феноменологическую, интеракционную.

Результаты и их обсужАение. Научная новизна исслеАования заключается в преАставлении основной категориальной еАиницей, отчасти объеАиняющей три базисные метолологические позиции, концепта «воплощенное Я », вк^ючающего в себя элементы Я-моделей и нарративные компоненты в единстве биопсихических, эмоциональных и когнитивно-поведенческих фракторов. Это открывает значимые Аля исслеАования самосознания в специальной психологии компоненты: биогенетический компонент, Я-модель, имплицитное «чувство Яџ), когнитивный компонент эксплицитной «идеи Я», повеАенческий компонент Я-репрезентаций, нарративный компонент Я-репрезентаций. Системный поАХоА к изучению самосознания Аиц с ограниченными возможностями здоровья затрагивает изучение специорики механизмов развития самосознания, своеобразия активности субъекта по отношению к себе и своему поведению, Я-ориентаций как поведенческого результата функционирования самосознания. Интересующие специального психолога механизмы развития самосознания миц с нарушениями развития следующие: самопринятие/самонеприятие, илентификация/ Аеилентификация, рефлексия/Аерефлексия, слияние/отграничение.

Заключение. Представленные направления изучения самосознания лиц с ограниченными возможностями зАоровья открывают необходимость разработки метолик, релевантных заАачам практической Аеятельности специального психолога в рамках помощи субъектам разного возраста, имеющим различные варианты дизонтогенеза. Разработка новых метоАОв И способов психологического возАействия на аАаптационно значимые компоненты самосознания поможет в фрормировании Аиффференцированных условий организации 
КУЗЬМИНА Т.И.

К ВОПРОСУ О ПЕРСПЕКТИВАХ ИССЛЕДОВАНИЯ САМОСОЗНАНИЯ В СПЕЦИАЛЬНОЙ ПСИХОЛОГИИ

РосСиЙский псИХолоГИЧЕСКИЙ ЖУРнАл, 2020, Т. 17, № 2, 5-16. doi: 10.21702/rpj.2020.2.1

КОРРЕКЦИОННАЯ ПСИХОЛОГИЯ

Аичностно-ориентированного взаимодействия в рамках психологического сопровожАения миц разного возраста с нарушениями развития.

\section{КАючевые слова}

Я-репрезентации, воплощенное Я, рефрлексия, дерефрлексия, слияние, отграничение, илентиорикация, деилентиорикация, самопринятие, самонеприятие

\section{Основные положения}

$\triangleright \Delta \wedge я$ изучения самосознания Аиц с нарушениями развития неАостаточно использовать преимущественно нарративные репрезентации, ввиАу наличия у многих субъектов Аиагностики специфики вербального самовыражения;

> СИстемНЫЙ поАХоА К ИзУчению самосознания Аиц С ограниченными возможностями зАОровья связан с решением исследовательских залач в контексте форомирования аспектов их Аичностного аАаптационного и интегративного потенциала;

> теоретический базис Аиагностики Аолжен вкАючать в себя нарративные и повеАенческие компоненты, представленные в еАинстве биопсихических, эмоциональных и когнитивно-повеленческих фракторов.

\section{Для цитирования}

Кузьмина, Т. И. (2020). К вопросу о перспективах исследования самосознания в специальной психологии. Российский психологический журнал, 17(2), 5-16. doi: 10.21702/rpj.2020.2.1

Дата получения рукописи: 15.05 .2020 Дата окончания рецензирования: 14.06 .2020 Дата принятия к публикации: 18.06.2020

\section{Введение}

Самосознание - одна из самых социально значимых категориальных характеристик личности и субъектности в контексте изучения представлений человека о себе и становления его общественного поведения. Развитое самосознание и способность субъекта к самопознанию формируют его умение пребывать в диалоге с собой и Другими, существовать в системе двойной открытости себе и миру. Формирование умения обращаться к себе, получать информацию о себе не только из внешних источников, но и от себя самого позволяет субъекту открыто включаться в неустранимые взаимоотношения с жизнью, принимая ее запросы и контекстуальные условия, формирующие модус бытия (Столин, 1983; Пантилеев, 1993; Чеснокова, 1977; Längle, 1990, 1992/1999; Newen, 2015).

Актуальность исследований поведенческих и регулятивных компонентов личности субъектов с ограниченными возможностями здоровья неоспорима, особенно при наличии у них негрубых нарушений развития, в связи с чем они могут быть адекватно адаптированы в социуме при условии полноценного психолого-педагогического сопровождения. Исследовательский интерес также представляют социализационные и интеграционные механизмы общественного поведения детей, подростков и взрослых с разнообразными нарушениями развития (Трошин, 1915; Выготский, 1983; Лубовский, 2017, 2018; Лебединская и Лебединский, 2018; Левченко, Приходько и Гусейнова, 2017). 
КУЗЬМИНА Т. И.

К ВОПРОСУ О ПЕРСПЕКТИВАХ ИССЛЕДОВАНИЯ САМОСОЗНАНИЯ В СПЕЦИАЛЬНОЙ ПСИХОЛОГИИ

РОССИЙСКИЙ пСИХОЛОГИЧЕСКИЙ ЖУРнАл, 2020, Т. 17, № 2, 5-16. doi: 10.21702/rpj.2020.2.1

КОРРЕКЦИОННАЯ ПСИХОЛОГИЯ

Психологическое изучение самосознания лиц с нарушением развития имеет ряд диагностических и интерпретационных трудностей, возникающих в связи с наличием качественного своеобразия интроспективного опыта, содержаний самоотчетов и вербальных репрезентаций субъектов с ограниченными возможностями здоровья даже при наличии легкой степени выраженности нарушений.

Изучая самосознание субъекта с нарушением развития только как некий нарратив, мы рискуем оказаться в эпистемологической ловушке (Parnas, Sass, \& Zahavi, 2013), поскольку выраженная ограниченность вербальных репрезентаций такого субъекта диагностики, ввиду наличия у него специфических вербальных способов самовыражения и недостаточности имеющегося у диагноста адекватного инструментария, позволившего бы преодолеть анализаторную, интеллектуальную, психологическую ограниченность субъекта и получить доступ к глубинным механизмам становления самости, может создать у исследователя иллюзию отсутствия самосознания или того, что принято называть самосознанием в контексте теории нарративного Я (Dennet, 1992; Schechtman, 2007; Newen, 2018a, 2018b; Galbusera \& Fellin, 2014; Parnas \& Gallagher, 2014; Parnas \& Bovet, 1995).

На наш взгляд, характер диагностических трудностей и последующие направления их преодоления могут быть определены в зависимости от занимаемых исследователем методологических позиций.

\section{Теоретическое обоснование}

Подход к изучению представлений человека о себе в рамках диагностического и прогностического исследования специфики психического состояния, ментальных или иных нарушений может основываться на трех исследовательских позициях: от первого, второго и третьего лица (Galbusera \& Fellin, 2014).

Объясняющая парадигма «третьего лица» в рамках когнитивной теории социального понимания содержит следующие теоретические допущения:

а) исследователь не имеет прямого доступа к психическим состояниям других людей;

б) между исследователем и исследуемым существует так называемый «ментальный разрыв»;

в) чтобы сделать вывод о психическом состоянии другого человека, от диагноста требуются дополнительные когнитивные усилия, поскольку, согласно концепции «внутреннего мира», наши знания о другом человеке не даны непосредственно в опыте, являясь набором субъективных ментальных предположений, основанных на симптоматическом анализе поведенческих проявлений при наблюдении за человеком;

г) результаты наблюдения являются опорой для создания предположений о состоянии Другого;

д) исследовательская позиция предполагает, что диагност в некоем отстраненном наблюдении пытается соотнести психическое состояние диагностируемого субъекта с рядом категориальных описаний в рамках общепринятых теорий и классификаций;

е) опыт диагностируемого непосредственно воспринимается и оценивается с точки зрения экспертной позиции исследователя, который, опираясь на обобщенно-теоретические базисные предположения, пытается зафиксировать психическое состояние субъекта диагностики как объективное и контекстуальное (Gallagher, 2001, 2008a; Galbusera \& Fellin, 2014).

Симуляционный подход «от первого лица» диктует необходимость опоры диагноста на феноменологический взгляд в попытке распознать состояние исследуемого. Феноменология в ее 
КУЗЬМИНА Т.И.

К ВОПРОСУ О ПЕРСПЕКТИВАХ ИССЛЕДОВАНИЯ САМОСОЗНАНИЯ В СПЕЦИАЛЬНОЙ ПСИХОЛОГИИ

РосСИЙСКИЙ пСИХоЛОГИЧЕСКИЙ ЖУРнАл, 2020, Т. 17, № 2, 5-16. doi: 10.21702/rpj.2020.2.1

КОРРЕКЦИОННАЯ ПСИХОЛОГИЯ

классической интерпретации не рассматривает сознание человека дискретно и атомистически, поскольку идентифицирует его как меняющийся поток взаимобусловленных явлений, нечто целостное, представляющее собой «вещь в себе». Диагностический фокус направлен на сознание, постигаемое через углубленное исследование опыта субъекта, запечатленного от первого лица (Parnas \& Gallagher, 2014). Значение приобретают следующие понятия: самость, переживание Я, самосознание, субъективная реальность, субъектность. Подход от «первого лица» призывает исследователя, открывшись некоему собственному переживанию другого человека, встретить его, получить впечатление, на основе которого смоделировать внутри себя ментальное состояние Другого, чтобы понять его, исходя из него самого, а не пытаться объяснить в процессе наблюдения с опорой на общеизвестные психологические теории (Gallagher, 2001, 2008a, 2012; Gallagher \& Daly, 2018). Сторонники данного подхода основным доказательством наличия ментального здоровья называют развитую рефлексию и эмпатию, поскольку предполагают, что одним из лучших способов открыть доступ к чужому опыту является процесс его представления через образное отождествление (Wiggins \& Schwartz, 2013).

Таким образом, в попытке интуитивно представить психическое состояние исследуемого, исследователь может понять: каково это «быть подобным ему/ей» или «быть им» (Stanghellini, $2007,2010)$. Данная теория не в состоянии решить проблему «ментального разрыва» между познающим и познаваемым субъектами. Она обращена к тотальной обобщенности собственного опыта диагноста со смещенным «центром тяжести» в сторону переживания и понимания субъекта диагностики, в отличие от теоретизирования и объяснения в подходе «от третьего лица» (Reddy \& Morris, 2004). Позиция «от первого лица» не уделяет должного внимания контекстуальному наполнению и интеракции как необходимым структурным и содержательным частям социального понимания (Gallagher, 2008b, 2013, 2018).

Интерактивная теория в рамках подхода «от второго лица» предлагает альтернативное подходам от «третьего» и «первого лица» объяснение социального познания, основанное на теоретических допущениях, содержащих представления об отсутствии разрыва между телом и сознанием субъекта и непризнании «ментального разрыва» между Я и Другим. Сторонники теории интеракции признают значимую роль тела в процессе взаимодействия, попутно отказываясь от картезианского дуализма, осуществляющего деление на тело и разум. С их точки зрения, основа понимания другого человека кроется в дорефлексивной интенциональной связи, когда персональные эмоции и интенции наличествуют в любом экспрессивном поведении, значимом для диагноста уже с самого начала взаимодействия (Thompson, 2007; Gallagher, 2012). В данном случае Я воплощено и имеет неразрывную связь с телом, поскольку, как считают сторонники данной теории, при взаимодействии с другим человеком мы можем видеть и опознавать его состояния в отсутствие необходимости теоретизировать по этому поводу. Дорефлексивное вовлечение в социальное познание возможно уже на этапе детского возраста, когда ребенок учится понимать другого человека не через осмысление, а через взаимодействие с ним на дорефлексивном уровне (Fivaz-Depeursinge \& Philipp, 2014; Fivaz-Depeursinge \& Corboz-Warnery, 1999; Reddy, 2008).

Согласно интерактивному подходу, самосознание - результат интеграции воплощенного базового аффективного потока, возникающего в связи с неким интенциональным объектом/субъектом, когда Я становится одновременно и деятелем и центром притяжения мысли. В процессе обработки запросов окружающего мира и поиска адекватного поведенческого ответа на них субъект сталкивается с многочисленными, разноплановыми, 
КУЗЬМИНА Т. И.

К ВОПРОСУ О ПЕРСПЕКТИВАХ ИССЛЕДОВАНИЯ САМОСОЗНАНИЯ В СПЕЦИАЛЬНОЙ ПСИХОЛОГИИ

РоссийскИй псИХологИЧЕСКИЙ ЖУРнАл, 2020, Т. 17, № 2, 5-16. doi: 10.21702/rpj.2020.2.1

КОРРЕКЦИОННАЯ ПСИХОЛОГИЯ

мультиконтекстуальными ситуациями, когда поведенческая реализация требует включения значимых аспектов Я как деятеля, а также набора аффективных диспозиций, являющихся конститутивной частью Я (Newen, 2015, 2018a, 2018b).

\section{Результаты и их обсуждение}

На наш взгляд, ни один из описанных выше подходов не является исчерпывающим в связи с большим количеством разноплановых задач, стоящих перед исследователем в области специальной психологии личности: описать и охарактеризовать структурно-содержательное наполнение самосознания, в том числе как регулятора социального поведения, влияющего на формирование социально-адаптивных стратегий интеграции в социум лиц с нарушенным развитием; обобщить и типологизировать выявленное качественное своеобразие самосознания; разработать направления и методики психологической помощи и сопровождения развития личности субъекта с ограниченными возможностями здоровья; сформировать пролонгированные программы психологической поддержки лиц с нарушениями развития всех возрастных категорий, с внедрением специальных адаптированных методик диагностики и психокоррекции. В связи с этим методологической точкой отсчета может стать системный, синергетически организованный подход, учитывающий и преимущества и ограничения имеющихся теоретико-методологических взглядов.

В специальной психологии личности на данном этапе ее развития в рамках подхода «от третьего лица» практически отсутствуют какие-либо обобщенно-теоретические типологии и концепции, отражающие специфику общих закономерностей аномального развития личности при наличии тех или иных нарушений. При этом накоплен ряд данных о специфических закономерностях аномального развития личности субъектов с ограниченными возможностями здоровья разных нозологических групп. Эти данные нуждаются в обобщении и систематизировании наряду с определением парадигмальных оснований их изучения, которые еще только предстоит создать.

Любая категоризация и опора на концептуальный базис облегчает выполнение задач диагноста при отнесении выделенного феномена к той или иной понятийной группе на основе имеющихся классификационных критериев. При этом именно разнообразные, полученные эмпирическим путем, данные о качественном своеобразии содержания исследуемых феноменов самосознания лиц с проблемами в развитии представляют собой уникальный фундамент построения методологических обобщений, функциональных моделей, позволяя реализовать исследовательский вектор «от практики к теории».

Подход «от первого лица» с его феноменологическим фокусом дает большое пространство для диагностической работы, открывает направление создания специальных методик исследования, учитывающих специфику самосознания лиц с отклонениями в развитии и позволяющих открыть специфику нарушений становления самосознания на разных возрастных этапах в контексте дифференцированных нозологических групп.

На основании такого подхода могут быть созданы специальные методики, в основу разработки которых положены представления о специфике вербальных и поведенческих репрезентаций индивида (например, в вербальном материале методик использованы: специфический лексический материал, полученный методом контент-анализа из речи субъектов диагностики, наборы типичных для их жизни ситуаций и т.д.) (Кузьмина, 2016). Однако не стоит забывать, что попытки диагноста рефлексивно и эмпатийно получать впечатления о человеке 
КУЗЬМИНА Т.И.

К ВОПРОСУ О ПЕРСПЕКТИВАХ ИССЛЕДОВАНИЯ САМОСОЗНАНИЯ В СПЕЦИАЛЬНОЙ ПСИХОЛОГИИ

РосСИйскИй пСИХолОГИЧЕСКИЙ ЖУРнАл, 2020, Т. 17, № 2, 5-16. doi: 10.21702/rpj.2020.2.1

КОРРЕКЦИОННАЯ ПСИХОЛОГИЯ

с отклонениями в развитии, максимально соотнестись с его репрезентирующимся опытом, ограничены в силу действующего философского принципа «аналогии», согласно которому феноменологическое восприятие ставит исследователя на позицию, когда по аналогии с нашим собственным опытом другие люди должны испытывать те же психические состояния, что и мы сами (Stanghellini, 2007). В связи с этим рефлексивные интенции условно здорового субъекта по отношению к субъекту с нарушениями развития ограничены заданными условиями принципиальной разницы «Я-моделей» (Metzinger, 2009, 2011, 2014) диагноста и диагностируемого, связанной с особенностью протекания психических процессов при нормативном и нарушенном развитии.

Опора на феноменологическую диагностику с ее подробными описаниями и качественным анализом дает возможность указать направления психологической помощи, но не раскрывает механизмов, с учетом которых данная помощь может процессуально осуществляться. Такой подход может помочь предположить, «что» можно сделать со специфическими особенностями, выделенными в результате диагностики, но не помогает в понимании того, «как» это реализовать, поскольку для последнего диагносту необходимо выходить из феноменологической открытости и получать обратную связь от субъекта диагностики именно в процессе интеракции.

Динамические изменения самосознания, которые выражаются в изменении поведения, отмечающегося в рамках новых, ранее не свойственных индивиду поступков, действий, реакций, могут быть зафиксированы именно с помощью интерактивного подхода, реализуемого в социальном взаимодействии, когда в течение установления динамических взаимоотношений в процессе диагностики данные, полученные преимущественно феноменологическим путем, будут уточняться и конкретизироваться.

Концептуальной единицей, базирующейся преимущественно на феноменологическом и интерактивном подходе, но отчасти объединяющей все три озвученные выше методологические позиции, может стать понятие «воплощенное Я», согласно которому способность к самопознанию определяется как способность индивида представлять свои состояния как принадлежащие ему самому, особенно (но не только) психические состояния, где такое представление о себе сочетается с сознательным опытом (Newen \& Vogeley, 2003).

Самосознание в контексте «воплощенного Я» включает: 1) эксплицитное самосознание; 2) имплицитное самосознание; 3) непосредственную самопрезентацию, не сопровождаемую каким-либо сознательным опытом. Удельный вес эксплицитного (сознательно доступного) или имплицитного (частично доступного или не доступного сознательно) в структуре и содержании Я, а также значимость непосредственной саморепрезентации в сочетании с некоторым сознательным опытом до конца не определены. Однако именно такой теоретический концепт, как воплощенное Я, являющийся основой и эксплицитного и имплицитного самосознания, согласно натуралистической теории, способен дать субъекту возможность предопределять себя, осуществлять антиципацию, прогностику и действие на основе прошлого опыта (Newen, 2018a).

Учитывая наличие трех аспектов самости: самости как биологического существа; специфического самоотношения, а именно способности формировать саморепрезентации неким «самонаправленным» образом (т. е. непосредственным, субъектным способом); «Я-модели» как способности признавать единство множества источников информации о себе, которые интегрируются биологической системой,-можно предложить концепт «воплощенное Я» (Newen, 2018a) 
КУЗЬМИНА Т. И.

К ВОПРОСУ О ПЕРСПЕКТИВАХ ИССЛЕДОВАНИЯ САМОСОЗНАНИЯ В СПЕЦИАЛЬНОЙ ПСИХОЛОГИИ

РоссийскИй псИХологИЧЕСКИЙ ЖУРнАл, 2020, Т. 17, № 2, 5-16. doi: 10.21702/rpj.2020.2.1

КОРРЕКЦИОННАЯ ПСИХОЛОГИЯ

в дополнение к «модели Я» и мозговым структурам (Metzinger, 2014), чтобы адекватно объяснить феномены самосознания, а также многие тесно связанные с ними явления. Реалистическое представление о человеке как «воплощенном Я» имеет решающее значение для того, чтобы он мог действовать здесь и сейчас или адекватно планировать свои действия.

На наш взгляд, изучение самосознания в рамках специальной психологии в перспективе развития должно реализовывать следующие направления:

- изучение самосознания, прежде всего, в его диалогической соотнесенности с внешним миром и внутренним миром субъекта, в аспекте значимости для регуляции общественного поведения сообразно интеграционным и адаптационным задачам его социализации;

- использование феноменологических, интерпретативных, интеракционных методологических позиций и моделей в их соотнесенности с доступностью использования не только для диагноста, но и для субъекта диагностики (например, феноменологический подход с использованием вербальных репрезентаций «от первого лица», предполагающий преимущественно нарративные трансляции интроспективного опыта, не может быть основополагающим для психологического изучения самосознания лиц с тяжелыми нарушениями речи, интеллектуальной недостаточностью, расстройствами аутистического спектра, нарушением слуха ввиду наличия у них выраженных нарушений вербальных репрезентаций);

- динамическое и пролонгированное изучение процесса развития самосознания лиц разного возраста (в том числе взрослого) в рамках разных нозологических групп с целью исследовать специфическое развитие механизмов формирования представлений о себе в контексте имеющегося нарушения;

- определение качественного своеобразия самосознания лиц с ограниченными возможностями здоровья в контексте выявления нарушенных и сохранных областей содержания формирования представлений о себе как Я-воспринимающем субъекте (Я-модель), Я-продуцирующем субъекте (чувство Я, идея Я), Я-деятеле (Я-репрезентация).

Опираясь на представления о концепте «воплощенное Я», включающем в себя элементы Я-моделей и нарративные компоненты, представленном в единстве биопсихических, эмоциональных и когнитивно-поведенческих факторов (Newen, 2018a), мы считаем целесообразным выделить следующие, значимые с точки зрения специальной психологии, компоненты «воплощенного Я»:

1. Биогенетический компонент, который определяется нозологической принадлежностью одного или нескольких первичных нарушений развития, т. е. медицинским диагнозом.

2. Я-модель, которая связана со способностью субъекта к адекватному отражению действительности, обработке информации, поступающей извне, в том числе в связи с собой.

3. Имплицитное «чувство Я», которое связано со способностью к эмоциональному невербализованному переживанию себя и Другого как деятеля. Я-модель и имплицитное чувство Я обеспечивают дорефлексивный уровень социального понимания, являющийся более онтогенетически ранним образованием, нежели рефлексивное понимание, затрагивающее уровень осмысления и вербальных репрезентаций. Дорефлексивное понимание, например, при нарушении интеллекта, является более сохранным звеном самосознания, нежели рефлексия. При попытке формирования рефлексивных умений у лиц с интеллектуальным недоразвитием с помощью воспитательного воздействия зачастую происходит блокировка дорефлексивного понимания как основного базиса интеракции, а полноценная рефлексия так 
КУЗЬМИНА Т.И.

К ВОПРОСУ О ПЕРСПЕКТИВАХ ИССЛЕДОВАНИЯ САМОСОЗНАНИЯ В СПЕЦИАЛЬНОЙ ПСИХОЛОГИИ

Российский психологИческий жУРнАл, 2020, Т. 17, № 2, 5-16. doi: 10.21702/rpj.2020.2.1

КОРРЕКЦИОННАЯ ПСИХОЛОГИЯ

и не формируется в силу интеллектуальных нарушений. Это формирует внушаемость - элемент качественного своеобразия самосознания, основанный на недоразвитии способности улавливать семантический контекст обращения и рефлексивно-суггестивные компоненты внешнего воздействия (Кузьмина, 2016).

4. Когнитивный компонент эксплицитной «идеи Я» связан со способностью формировать осознанную картину себя, представления о себе, Я-концепцию как в рамках наличной ситуации, так и в соотнесении с прогностическими компонентами сознания (формирование образа Я будущего, настоящего и прошлого).

5. Поведенческий компонент Я-репрезентаций, который связан со способностью осуществлять действия и поступки на основе персонального анализа ситуации (формирование ситуационной оценки, принятие решения, формирование внутреннего плана действий по реализации решения, осуществление поступка не только в контексте его психофизических, но и нравственно ориентированных основ).

6. Нарративный компонент Я-репрезентаций, который связан со способностью выражать в понятном для окружающих вербальном плане имеющиеся представления о себе, о своих поступках и морально-нравственных оценках действительности, т. е. со способностью к вербальному диалогу.

С практико-ориентированной точки зрения, для формирования социально-личностного адаптационного потенциала лиц с нарушениями развития в контексте психологического сопровождения, по нашему мнению, следует обратить внимание на изучение специфики механизмов развития самосознания, реализующихся в некоей активности субъекта по отношению к себе и приводящих к формированию Я-ориентаций как поведенческого результата функционирования самосознания.

Интересующие специального психолога механизмы развития самосознания лиц с нарушениями развития следующие:

1. Самопринятие/самонеприятие (данные механизмы континуально связаны с критичным отношением субъекта к имеющемуся состоянию или иным своим особенностям, варьируются от полного принятия себя, некритичного отношения и неадекватно завышенной самооценки до излишней критичности в свой адрес, неадекватно завышенных требований к себе, неприятия себя. Особенно ярко воздействие этих механизмов может проявиться, например, при позднем возникновении нарушения дефицитарного типа).

2. Идентификация/деиндентификация (данные механизмы, с одной стороны, связаны со способностью субъекта к принятию социальной роли и соответствующего ей поведения, отождествления себя с определенными социальными группами, в том числе с другими людьми, имеющими подобное нарушение. С другой стороны - с растождествлением себя с такими негативно окрашенными социальными стигматами, как «больной», «инвалид», «дурачок» и т.д. Особенно ярко воздействие этих механизмов может проявиться при, например, адаптационных проблемах).

3. Рефлексия/дерефлексия (эти механизмы, с одной стороны, связаны со способностью обратиться к себе, к своим переживаниям, их переосмыслением, а с другой-со способностью переключить фокус внимания с себя на смыслы, ценности, перспективы и контексты. Особенно ярко воздействие этих механизмов может проявиться, например, при профессиональном самоопределении, формировании перспективного планирования линии жизни, при преодолении фиксации на собственных страхах перед будущей самостоятельностью, 
КУЗЬМИНА Т. И.

К ВОПРОСУ О ПЕРСПЕКТИВАХ ИССЛЕДОВАНИЯ САМОСОЗНАНИЯ В СПЕЦИАЛЬНОЙ ПСИХОЛОГИИ

РоссийскИй псИХологИЧЕСКИЙ ЖУРнАл, 2020, Т. 17, № 2, 5-16. doi: 10.21702/rpj.2020.2.1

КОРРЕКЦИОННАЯ ПСИХОЛОГИЯ

приобретением специальности, возможной социальной неуспешностью или страхами ухудшения состояния здоровья).

4. Слияние/отграничение (эти механизмы связаны, с одной стороны, со спецификой взаимоотношения субъекта со значимыми близкими людьми, когда выраженно нарушаются или не формируются его границы, когда он утрачивает интенции к общению с интересными ему людьми, особенно при наличии выраженных дизонтогенетических проявлений и анализаторных ограничений; с другой стороны, имеют связь со способностью субъекта сепарироваться от семьи, избежать иждивенческих позиций, формировать свое пространство отношений, в связи с реализацией собственных интенций к общению и формированию ответственной (иногда гиперответственной) самостоятельной позиции («Я сам»). Особенно ярко воздействие этих механизмов может проявиться, например, при нарушениях семейного воспитания: поддерживающей и потворствующей гиперпротекции, формировании у ребенка повышенной моральной ответственности).

Также с точки зрения реализации социально-адаптивных стратегий поведения заслуживают отдельного внимания действия субъекта с нарушением развития в области самопознания в контексте анализа собственного поведения: 1) умение воспринять (ситуацию и свое состояние), 2) почувствовать (охарактеризовать свое эмоциональное переживание), 3) понять (выделить индивидуальные основы поступка), 4) объяснить (свое поведение и поведение других по отношению к себе).

С диагностической точки зрения интересны:

1) самонаблюдение как способность видеть себя деятелем в рамках поведенческой активности, взаимодействия с окружающими и с самим собой;

2) самовосприятие как способность получать впечатления, представление о себе, структурировать собственный образ;

3) самооценивание как способность соотносить свои индивидуальные особенности с имеющимся в сознании эталоном на предмет их ценности, положительной и отрицательной личностной и социальной значимости;

4) самоутверждение как способность достижения (и потребность в достижении) определенного социального, психологического и физического статуса;

5) самоконтроль как способность контролировать свои поведенческие проявления сообразно ситуации и стоящим перед субъектом целям и задачам;

6) саморегуляция как способность субъекта самостоятельно воздействовать на свою психику с целью изменения тех или иных ее значимых характеристик (например, эмоциональных состояний, патохарактерологических проявлений).

Я-ориентации в данном контексте могут рассматриваться как результат реализации механизмов развития самосознания в рамках персональной активности субъекта с ограниченными возможностями здоровья и как базис интенций такого субъекта по отношению к миру. Они могут быть представлены следующими типами:

1) мировоззренческие Я-ориентации (картина себя и мира, морально-нравственные понятия, установки, ценности и смыслы);

2) поведенческие Я-ориентации (опознание ситуации, принятие решений, формирование стратегии реализации решений, поступок);

3) рефлексивные Я-ориентации (корректировки мировоззренческих и поведенческих Я-ориентаций в процессе самопознания, обращения к себе, осмысления полученного опыта). 
КУЗЬМИНА Т.И.

К ВОПРОСУ О ПЕРСПЕКТИВАХ ИССЛЕДОВАНИЯ САМОСОЗНАНИЯ В СПЕЦИАЛЬНОЙ ПСИХОЛОГИИ

РосСиЙский псИХолоГИЧЕСКИЙ ЖУРнАл, 2020, Т. 17, № 2, 5-16. doi: 10.21702/rpj.2020.2.1

КОРРЕКЦИОННАЯ ПСИХОЛОГИЯ

\section{Заключение}

Таким образом, изучение самосознания в рамках специальной психологии имеет широкий спектр перспективных направлений, связанных, прежде всего, с прикладным значением развития этого персонального образования для становления личностного адаптационного потенциала лиц с ограниченными возможностями здоровья и реализации его в социальном взаимодействии и общественном поведении.

Необходимые направления научного поиска заключаются в разработке парадигмальных оснований и методологических подходов к исследованию Я-структур, а также к описанию необходимых и достаточных условий развития персональной активности субъекта по отношению к себе и своему поведению. Для обеспечения выбора исследовательского вектора, релевантного задачам научного поиска в контексте специальной психологии личности, необходимо использовать комплексный подход, основанный на синтезе основополагающих концепций социального понимания (теоретико-объясняющей, феноменологической, интеракционной).

В данном теоретическом исследовании предпринята попытка методологически обосновать, сформировать и обозначить как перспективное направление не только сам системный подход к изучению самосознания лиц с нарушениями развития, но и оценку его потенциальной прикладной реализации, что имеет большое значение для развития представлений об общих закономерностях аномального развития личности и прогностического определения специфики личностной организации субъектов с ограниченными возможностями здоровья.

Означенный в исследовании системный подход может стать базовым основанием для разработки практических диагностических методик и направлений психокоррекции в работе с представителями различных нозологических групп, являющихся субъектами специальной психологии, что открывает необходимость разработки новых методов и способов изучения самосознания и его адаптационно значимых компонентов у лиц с различными дизонтогенетическими проявлениями (например, таких, как вербальные и невербальные ситуационно-диагностические методы) (Кузьмина, 2016). Также данный подход может быть использован для разработки дифференцированных условий организации личностно-ориентированного взаимодействия в рамках психологического сопровождения лиц разного возраста с нарушениями развития.

Также данные, полученные при разработке и апробации приемов и методов диагностики самосознания в рамках комплексного подхода и представляющие собой описание качественного своеобразия представлений субъекта с ограниченными возможностями здоровья о себе, могут быть впоследствии включены в список критериальных параметров дифференциальной диагностики в области коррекционной психологии.

\section{Литература}

Выготский, Л. С. (1983). Собрание сочинений в 6 т.: Т. 5. Основы дефектологии. Москва: Педагогика.

Кузьмина, Т. И. (2016). Психологическая диагностика самосознания лиц разного возраста с интеллектуальной недостаточностью. Москва: Национальный книжный центр.

Лебединская, К. С. и Лебединский, В. В. (2018). Нарушения психического развития в детском и подростковом возрасте. Учебное пособие для вузов. Москва: Академический проект. 
КУЗЬМИНА Т. И.

К ВОПРОСУ О ПЕРСПЕКТИВАХ ИССЛЕДОВАНИЯ САМОСОЗНАНИЯ В СПЕЦИАЛЬНОЙ ПСИХОЛОГИИ

РоссийскИй псИХологИЧЕСКИЙ ЖУРнАл, 2020, Т. 17, № 2, 5-16. doi: 10.21702/rpj.2020.2.1

КОРРЕКЦИОННАЯ ПСИХОЛОГИЯ

Левченко, И. Ю., Приходько, О. Г. и Гусейнова, А. А. (2017). Специальные условия доступности среднего профессионального образования для лиц с инвалидностью и ограниченными возможностями здоровья. Коррекционная педагогика: теория и практика, 3, 15-37.

Лубовский, В. И. (2017). Инклюзия - тупиковый путь для обучения детей с ограниченными возможностями. Современное дошкольное образование. Теория и практика, 2, 32-37.

Лубовский, В. И. (2018). Что такое «структура дефекта»? Специальное образование, 4, 145-157.

Пантилеев, С. Р. (1993). Методика исследования самоотношения. Москва: Смысл.

Столин, В. В. (1983). Самосознание личности. Москва: Издательство Московского Университета.

Трошин, Г. Я. (1915). Антропологические основы воспитания. Сравнительная психология нормальных и ненормальных детей. Петроград: Школа-лечебница д-ра мед. Г. Я. Трошина.

Чеснокова, И. И. (1977). Проблема самосознания в психологии. Москва: Наука.

Dennett, D. C. (1992). Consciousness explained. London: Penguin Books.

Fivaz-Depeursinge, E., \& Corboz-Warnery, A. (1999). The primary triangle: A developmental systems view of mothers, fathers, and infants. Basic Books.

Fivaz-Depeursinge, E., \& Philipp, D. A. (2014). The baby and the couple. Understanding and treating young families. Routledge.

Galbusera, L., \& Fellin, L. (2014). The intersubjective endeavor of psychopathology research: Methodological reflections on a second-person perspective approach. Frontiers in Psychology, 5, 1150. doi: 10.3389/fpsyg. 2014.01150

Gallagher, S. (2001). The practice of mind: Theory, simulation or primary interaction? Journal of Consciousness Studies, 8(5-7), 83-108.

Gallagher, S. (2008a). Direct perception in the intersubjective context. Consciousness and Cognition, 17(2), 535-543. doi: 10.1016/j.concog.2008.03.003

Gallagher, S. (2008b). Inference or interaction: Social cognition without precursors. Philosophical Explorations, 11(3), 163-174. doi: 10.1080/13869790802239227

Gallagher, S. (2012). In defense of phenomenological approaches to social cognition: Interacting with the critics. Review of Philosophy and Psychology, 3, 187-212. doi: 10.1007/s13164-011-0080-1

Gallagher, S. (2013). A pattern theory of self. Frontiers in Human Neuroscience, 7, 443. doi: 10.3389/ fnhum.2013.00443

Gallagher, S., \& Daly, A. (2018). Dynamical relations in the self-pattern. Frontiers in Psychology, 9, 664. doi: 10.3389/fpsyg.2018.00664

Längle, A. (1990). Existential analysis psychotherapy. The International Forum of Logotherapy. Journal of Search for Meaning, 13(2), 17-19.

Längle, A. (1992/1999). Die existentielle motivation der person. Existenzanalyse, 16(3), 18-29.

Metzinger, T. (2009). The Ego-Tunnel. The science of the mind and the myth of the self. New York: Basis Books.

Metzinger, T. (2011). The no-self alternative. In S. Gallagher (Ed.), The Oxford handbook of the self (pp. 279-296). Oxford: Oxford University Press.

Metzinger, T. (2014). First-order embodiment, second-order embodiment, third-order embodiment. In L. Shapiro (Ed.), The Routledge handbook of embodied cognition (pp. 272-286). London: Routledge.

Newen, A. (2015). Understanding others - The Person Model Theory. In T. Metzinger, J. M. Windt (Eds.), Open MIND (pp. 1-28). Frankfurt am Main: MIND Group. doi: 10.15502/9783958570320

Newen, A. (2018a). The embodied self, the pattern theory of self, and the predictive mind. Frontiers in Psychology, 9, 2270. doi: 10.3389/fpsyg.2018.02270 
КУЗЬМИНА Т.И.

К ВОПРОСУ О ПЕРСПЕКТИВАХ ИССЛЕДОВАНИЯ САМОСОЗНАНИЯ В СПЕЦИАЛЬНОЙ ПСИХОЛОГИИ

Российский психологИческий жУРнАл, 2020, Т. 17, № 2, 5-16. doi: 10.21702/rpj.2020.2.1

КОРРЕКЦИОННАЯ ПСИХОЛОГИЯ

Newen, A. (2018b). The person model theory and the question of situatedness of social understanding. In F. Newen, L. De Bruin, S. Gallagher (Eds.), The Oxford handbook of 4E cognition (pp. 469-492). Oxford: Oxford University Press. doi: 10.1093/oxfordhb/9780198735410.013.25

Newen, A., \& Vogeley, K. (2003). Self-representation: Searching for a neural signature of self-consciousness. Consciousness and Cognition, 12(4), 529-543. doi: 10.1016/S1053-8100(03)00080-1

Parnas, J., \& Bovet, P. (1995). Research in psychopathology: Epistemologic issues. Comprehensive Psychiatry, 36(3), 167-181. doi: 10.1016/0010-440X(95)90078-A

Parnas, J., \& Gallagher, S. (2014). Phenomenology and the interpretation of psychopathological experience. In L. J. Kirmayer, R. Lemelson, C. A. Cummings (Eds.), Re-visioning psychiatry: Cultural phenomenology, critical neuroscience, and global mental health (pp. 65-80). Cambridge, Cambridge University Press. doi: $10.1017 /$ CBO9781139424745.006

Parnas, J., Sass, L. A., \& Zahavi, D. (2013). Rediscovering psychopathology: The epistemology and phenomenology of the psychiatric object. Schizophrenia Bulletin, 39(2), 270-277. doi: 10.1093/ schbul/sbs153

Reddy, V. (2008). How infants know minds. Cambridge, MA: Harvard University Press. doi: 10.2307/j. ctv10vm0qv

Reddy, V., \& Morris, P. (2004). Participants don't need theories: Knowing minds in engagement. Theory \& Psychology, 14(5), 647-665. doi: 10.1177/0959354304046177

Schechtman, M. (2007). Stories, lives, and basic survival: A refinement and defense of the narrative view. Royal Institute of Philosophy Supplements, 60, 155-178. doi: 10.1017/S1358246107000082

Stanghellini, G. (2007). The grammar of the psychiatric interview. Psychopathology, 40, 69-74. doi: $10.1159 / 000098486$

Stanghellini, G. (2010). A hermeneutic framework for psychopathology. Psychopathology, 43, 319-326. doi: 10.1159/000319401

Thompson, E. (2007). Mind in life: Biology, phenomenology, and the science of mind. Cambridge, MA: Harvard University Press.

Wiggins, O. P., \& Schwartz, M. A. (2013). Phenomenology and psychopathology: In search for a method. In G. Stanghellini, T. Fuchs (Eds.), One century of Karl Jaspers' general psychopathology (pp. 16-26). Oxford University Press.

Конфликт интересов отсутствует 